\title{
Evaluating Land Use Intensification Based on Entropy Method --- A Case Study of Hefei
}

\author{
Lan Yao ${ }^{1} \&$ Qi Yin ${ }^{1}$ \\ ${ }^{1}$ College of Economics and Management, Sichuan Agricultural University, Chengdu, China \\ Correspondence: Qi Yin, College of Economics and Management, Sichuan Agricultural University, 211 \\ Gongpinghuimin St, Wenjiang District, Chengdu 611130, China. E-mail: yinqi226@yahoo.com.cn
}

\author{
Received: February 11, $2012 \quad$ Accepted: March 13, $2012 \quad$ Published: June 1, 2012 \\ doi:10.5539/ass.v8n7p54 \\ URL: http://dx.doi.org/10.5539/ass.v8n7p54
}

\begin{abstract}
In this paper, we establish the index system of urban land intensive use evaluation from four aspects: land investment level, land utilization level, land output effect, land use ecological benefits. The entropy method is used to calculate indexes which measure the land intensive utilization in Hefei. According to the comprehensive evaluation model we can draw a conclusion that although the land intensive use level of Hefei was ascending from 2004 to 2008, it is still at low level in 2008. Finally, we make suggestions about how to improve the intensive use level in Hefei with the help of the integrated assessment value of each rule layer. The conclusion indicate that Hefei should solve land utilization problems by setting the target for land intensive utilization, optimizing the land use structure, improving the urban environment, enhancing the land use level, changing the direction of land utilization, only in theses ways the land utilization of Hefei will be intensive.
\end{abstract}

Keywords: land intensive use, entropy method, Hefei

\section{Introduction}

It is an important content of the regional land intensive utilization research to evaluating the intensification of land utilization. Quantitative evaluation of land intensive use level should be done to measure whether the land is intensive used. Firstly the land intensive use evaluation model and a set of evaluation index system should be established to analysis the problems which exist in the land intensive utilization.

The concept of urban land intensive utilization comes from the agricultural land intensive utilization, but its connotation is richer and more complicate. At present, Chinese and foreign scholars have not reached an agreement about this concept. Domestic scholars switched their research focus of land intensive utilization from the pursuit of economic benefit to comprehensive benefit which suggests that the understanding about land intensive utilization is gradually matured. The purpose of urban land intensive utilization is to improve the use ratio of urban land so that the society, economy and environment profits will be enhanced as well. To increase the input of stock land and improve the management is the common way to improve the use ratio of land. But the city size and rational distribution must be considered in this progress.

China has an enormous population so that the land becomes scarce resource. The agricultural acreage in China is 1.837 billion $\mathrm{mu}$ at 2004 . The per capita acreage is $1.41 \mathrm{mu}$ which only meets $43 \%$ of the world's average. This is the reality of China. In nowadays, Chinese economy is growing rapidly, the land, as an exiguous and fundamental resource, plays a significant role in the development of the economy. It is wrong that urban blind expansion for economic benefit. Thus, to improve the utilization ratio of urban land constantly by carrying out the intensive land use evaluation not only is beneficial to optimize the utilization of urban land resources, but also transforms the city's development mode. The intensive land use evaluation also is an essential link of land survey and effective mean to learn about the economic quality of land. The scientific index system is established to evaluate the level of urban land utilization in this paper. This system also has significant meaning for quantifying the current status and trend of land intensive use in Hefei and analyzing the influencing factor and existing problems.

\section{The Information of Researched Area}

Hefei is located in the central of Anhui province. Two rivers, Yangtze River and Huaihe River, run nearby Hefei 
which lying to the bank of Chaohu Lake. Hefei is adjacent to the Yangtze River delta economic circle. It is the political, economical, cultural, informational, financial and commercial center of Anhui province. Yaohai, Luyang, Shushan, Baohe are the four districts of Hefei. The administrative district covers an area of 7029.48 square kilometers which built up area covers 304 square kilometers. By the end of 2009, Hefei has a total population of 5.01 million, including urban household register population 2.4 million. The permanent population in the city is above 3 million, and the non-agricultural population is 3.1 million.

\section{Evaluation of Intensive Land Utilization}

\subsection{Selection of Evaluated Index and Establishment of Evaluated System}

How to choose indexes is the most important but hardest link. The chosen index has to not only be comprehensive but also meet the system's demand. The urban land use evaluation system is based on defining the connotation of land intensive utilization in order to make cities developing sustainable, lawful and efficiency. Land use level and land input-output level are the two aspects to build the land evaluation system combined with local financial situation.

The paper chooses the following indexes as a Hefei land intensive use evaluation index system by referring to literatures and reality.

Table 1. City land intensive use evaluation index system

\begin{tabular}{|c|c|c|}
\hline Target layer & Rule layer & Index layer \\
\hline \multirow{19}{*}{ 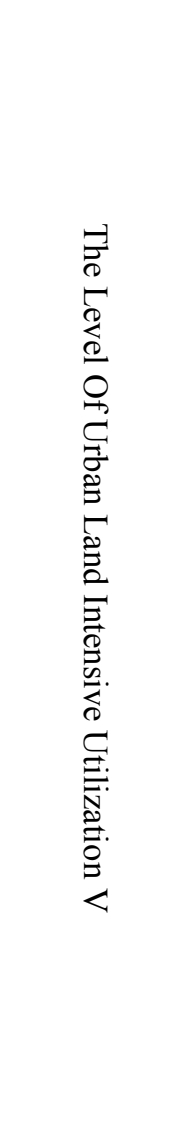 } & \multirow{5}{*}{ Land investment levelV $V_{1}$} & Investedassets in per square \\
\hline & & kilometer $\mathrm{X}_{1}$ \\
\hline & & $\begin{array}{l}\text { Financial expenditure in per } \\
\text { square kilometer } \mathrm{X}_{2}\end{array}$ \\
\hline & & Employee in per square \\
\hline & & kilometer $\mathrm{X}_{3}$ \\
\hline & \multirow{4}{*}{ Land utilization levelV $\mathrm{V}_{2}$} & Population density $\mathrm{X}_{4}$ \\
\hline & & Land utilization ratio $\mathrm{X}_{5}$ \\
\hline & & Per-capita construction land $\mathrm{X}_{6}$ \\
\hline & & Financial revenue in per square \\
\hline & \multirow{6}{*}{ Land output effect $V_{3}$} & kilometer $\mathrm{X}_{7}$ \\
\hline & & Retail sales of consumer goods \\
\hline & & in per square kilometer $\mathrm{X}_{8}$ \\
\hline & & Production value of secondary \\
\hline & & and tertiary sectors in per square \\
\hline & & kilometer $\mathrm{X}_{9}$ \\
\hline & \multirow{4}{*}{ Land use ecological benefits $\mathrm{V}_{4}$} & Per-capita road area $X_{10}$ \\
\hline & & Per-capita green area $X_{11}$ \\
\hline & & Green coverage rate in built up \\
\hline & & area $X_{12}$ \\
\hline
\end{tabular}

\subsection{The Construction of Evaluation Model}

In this paper, the entropy method is chosen to be the method to evaluate the situation of the intensive land utilization in Hefei. Entropy is an objective method which is capable to report the differences between indexes accurately. Generally speaking, the faster the index changes, the smaller entropy index gets. The greater its utility value is, the greater the index weight is. The smaller the index weight is conversely.

\subsubsection{Confirm the Index Weight}

(1) Construct the index system matrix

Assuming that $m$ has a quantitative evaluate index $X_{1}, X_{2}, \ldots, X_{m}$, and a participating object is $n$, thus it can 
compose a matrix by the raw data $\mathrm{A}=\left\{\mathrm{X}_{\mathrm{ji}}\right\}\left(\mathrm{X}_{\mathrm{ji}} \mathrm{i}=1,2, \ldots \mathrm{m} ; \mathrm{j}=1,2, \ldots \mathrm{n}\right)$.

(2) Standardization

Because each index we selected has different unit, we must deal with the index by standardization before the calculation of next step. Data standardization has variety of ways, in this paper, the following formula is used for standardizing the index: $\mathrm{P}_{\mathrm{ji}}=\frac{X_{j \mathrm{ji}}}{\sum_{j=1}^{\mathrm{n}} X_{j i}} \quad(\mathrm{i}=1,2,3, \ldots, \mathrm{m} ; \mathrm{j}=1,2,3, \ldots, \mathrm{n}$.)

(3) Calculate the entropy of participating index

$$
E_{\mathrm{i}}=-\mathrm{k} \sum_{j=1}^{n} p_{j i} \ln p_{j i}, \text { thereinto, } \mathrm{k}=1 / \mathrm{ln}
$$

(4) Calculate the discrimination factor

$$
d_{i}=1-E_{i}
$$

(5) Decide the weight coefficient

$$
e_{i}=\frac{d_{i}}{\sum_{i=1}^{m} d_{i}}
$$

\subsubsection{Calculate the Score of Evaluation Index}

The actual value of each index in research time every year will be added as the desired value, and divided the actual value of each index by the desired value, then we can get the score of each index in the year.

$$
Q_{j i}=\frac{X_{\mathrm{ji}}}{\sum X \mathrm{ji}}(\mathrm{i}=1,2,3, \ldots, \mathrm{m} ; \mathrm{j}=1,2,3, \ldots, \mathrm{n} .)
$$

$\mathrm{Q}_{\mathrm{ji}}$ is the value after standardization, and $\mathrm{X}_{\mathrm{ji}}$ is the actual value of evaluation index.

\subsubsection{Establishment of the Comprehensive Evaluation Model}

According to use the method of entropy, we ascertain the weight of each index and the score of the evaluation index, it can get the urban land intensive use scores through the comprehensive evaluation model: $Y_{\mathrm{i}}=\sum e_{i} Q_{j i} \quad(\mathrm{i}=1,2,3, \ldots, \mathrm{m} ; \mathrm{j}=1,2,3, \ldots, \mathrm{n}$.$) .$

As the evaluation indexes weights are less than or equal to one, and the value of evaluation indexes are less than or equal to one, so it can be sure that the urban land intensive use value which determined by comprehensive evaluation is less than or equal to one. Therefore, we can draw a conclusion that if the urban land intensive use value $\mathrm{Yi}=0$, the level of urban land intensive use will be the lowest, and when $\mathrm{Yi}=1$, the level of urban land intensive utilization is at the top of its form. It can get the following estimation scale of urban land intensive utilization through the review of the literature.

Table 2. Estimation scale of urban land intensive utilization

\begin{tabular}{cccccc}
\hline Layer level & Higher & High & Medium & Low & Lower \\
\hline Score range & $0.8 \sim 1$ & $0.6 \sim 0.8$ & $0.4 \sim 0.6$ & $0.2 \sim 0.4$ & $0 \sim 0.2$ \\
\hline
\end{tabular}

\section{Evaluate Result}

According to the data provided by 2009 Hefei statistics yearbooks, we get the original value of each index about land intensive utilization of Hefei from 2004 to 2008. According to the original value of the evaluation indexes and the entropy method mentioned above we can get the weight of each index about land intensive utilization in Hefei. 
Table 3. Indexes weights of evaluation about land intensive use level in Hefei

\begin{tabular}{|c|c|c|c|c|}
\hline Target layer & Rule layer & Weight & Index layer & Weight \\
\hline \multirow{12}{*}{ 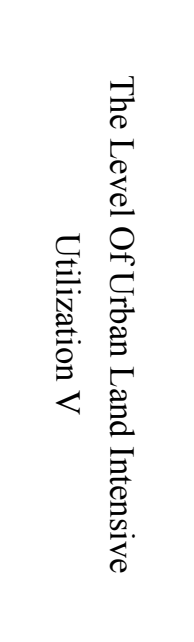 } & \multirow{3}{*}{$\begin{array}{l}\text { Land investment } \\
\qquad \text { levelV }_{1}\end{array}$} & \multirow{3}{*}{0.6147} & $\mathrm{X}_{1}$ & 0.3717 \\
\hline & & & $\mathrm{X}_{2}$ & 0.2389 \\
\hline & & & $X_{3}$ & 0.0040 \\
\hline & \multirow{3}{*}{$\begin{array}{l}\text { Land utilization } \\
\quad \text { levelV }_{2}\end{array}$} & \multirow{3}{*}{0.0095} & $\mathrm{X}_{4}$ & 0.0013 \\
\hline & & & $\mathrm{X}_{5}$ & 0.0002 \\
\hline & & & $\mathrm{X}_{6}$ & 0.0081 \\
\hline & \multirow{3}{*}{$\begin{array}{l}\text { Land output } \\
\text { effectV }_{3}\end{array}$} & \multirow{3}{*}{0.3573} & $\mathrm{X}_{7}$ & 0.1603 \\
\hline & & & $\mathrm{X}_{8}$ & 0.0814 \\
\hline & & & $\mathrm{X}_{9}$ & 0.1156 \\
\hline & Land use & \multirow{3}{*}{0.0185} & $\mathrm{X}_{10}$ & 0.0044 \\
\hline & ecological & & $\mathrm{X}_{11}$ & 0.0092 \\
\hline & benefits $V_{4}$ & & $\mathrm{X}_{12}$ & 0.0049 \\
\hline
\end{tabular}

According to the evaluation index weight of Table 3 combined with the comprehensive evaluation model, we can get the comprehensive evaluation score of land intensive use in Hefei.

Table 4. Comprehensive evaluation score of land intensive use in Hefei

\begin{tabular}{cccccc}
\hline & 2008 & 2007 & 2006 & 2005 & 2004 \\
\hline Land investment level & 0.5902 & 0.4359 & 0.3365 & 0.2565 & 0.2249 \\
Land utilization level & 0.0061 & 0.0056 & 0.0056 & 0.0057 & 0.0056 \\
Land output effect & 0.3250 & 0.2503 & 0.2011 & 0.1636 & 0.1319 \\
$\begin{array}{c}\text { Land use ecological } \\
\text { benefits }\end{array}$ & 0.0113 & 0.0119 & 0.0108 & 0.0104 & 0.0111 \\
$\begin{array}{c}\text { Level of intensive land } \\
\text { utilization }\end{array}$ & 0.3445 & 0.2460 & 0.1795 & 0.1288 & 0.1012 \\
\hline
\end{tabular}

\section{Analysis of the Appraisal Result}

The land intensive use level can be evaluated by the time aspect. It also can be compared with other cities. In this paper, the time aspect is chosen to evaluate the land intensive use level. It can draw the following conclusions about the level of land intensive utilization in Hefei through the calculation above and Table 4.

\subsection{Analysis of the Comprehensive Score of Rule Layer}

The comprehensive evaluation value of land investment level came in the first place in the four rule layers. It shows that the level of land investment plays an important rule in land intensive utilization. The comprehensive evaluation value of land investment level is not high enough, which also tells us that the investment level of Hefei is promising. The level of the land intensive use in this region will be improved while the government increases the land investment.

The comprehensive score of land out put effect came in the second place in Hefei from 2004 to 2008, and all of the land output effect indexes are economic indexes. It illustrates that the local economy keeps a good momentum on development in this period. The output will increase as the improvement of input in the future.

The value of ecological benefits about land utilization is 0.0111 , it shows that the input for virescence and environmental protection is not enough in land utilization of Hefei. It reflects that this region hasn't paid much attention to the investment of urban ecological environment construction.

In the four rule layers, the comprehensive value of land utilization level is the lowest. Local governments should increase the level of land utilization by taking measures in the future.

\subsection{Analysis of the Level about Intensive Land Utilization}

The level of land intensive utilization of Hefei showed a rising trend from2004 to 2008 which the highest score was only 0.3445 in 2008. It means the level of land intensive utilization is still at a low level in 2008. It reflects 
that Hefei has a great potential in land intensive utilization. In the future, all investments especially land ecological and land utilization investments should be increased in the progress of urban land development in Hefei referring to the front analysis. Local economy and social development situation should be considered as well. Only in this way will Hefei's urban land utilization be in the intensive direction.

\section{Conclusions}

To solve the problems which existed in the land intensive utilization of Hefei, a few suggestions are noted below:

Set the target for land intensive utilization: Firstly, a clear target of land intensive utilization is demanded in the new ground of drawing up the land use planning, the target would be to take the first steps toward the problems exited in the land utilization. Secondly, government plays a management role in the implementation of land use planning, it will be responsible for execution of policy and strengthen the policy advocacy, so the land utilization will be more intensive gradually.

Optimize the land use structure: urban land use structure is a significant factor to the scene of a city. Many researches indicate that the developed countries and regions optimize the land use structure in order to change land extensive utilization to intensive and improve the output rate. The land use structure in Hefei has yet to be improved through the raw data. For example, road area ratio should be expanded as the development of social economy. It can improve the land intensive utilization through adjusting the land use structure reasonably.

Improve the urban environment: city park and greenbelt are important parts of urban environment which reflect to the urban sustainable development. The comprehensive rating value of land ecological utilization in Hefei is low. Thus, the region should pay attention to protect the ecological environment. It can raise the level of land ecological utilization by increasing urban green area and the investment of environmental protection facilities.

Enhance the land use level: the lower land use level is, the higher land use potential is. Hefei city should increase capital input per unit area continually combined with its development situation in order to improve the input-output ratio gradually. Finally the land utilization of Hefei will be intensive.

Change the direction of land utilization: The government should take both the ground and underground as one piece to make the long-term construction plan, thus, government should focus on utilizing and constructing ground and underground space in urban environment where land is scarce. The land capacity rate and building height can be improved if fund and technology is permitted. Enterprises are encouraged to develop towards space in order to improve land space utilization rate. More efficient subway system, underground tunnel, stores and parking garages should be built in the future.

\section{References}

Cao, Yingui, Yuan, Chun, Wang, Jing, \& Zheng, Xinqin. (2008). Change of Regional Urban land intensive use and analyses on influential factors. Progress in geography, 27(3), 86-93.

Fan, Min, Liu, Yaolin, \& Wang, Hanhua. (2009). A study on intensified utilization and evaluation of urban land based on coordination level model. Science of Surveying and Mapping, 34(1), 144-146.

He, Fang. (2003). Urban land intensive utilization and its potential evaluation. Tongji university press.

Jiang, Zhixiang, \& Ma, Caixue. (2009). Research on evaluation of urban land intensive utilization --- a case study in Zaoyang city. Agricultural science and technology, 20(5), 55-56.

Lin, Jian, \& Chen, Qihui. (2002). How to use the land - the connotation and index evaluation about urban land intensive utilization. China land science, 16(4), 26-29.

Liu, Yang, Zheng, Cailing, \& Tang, Zhixin. (2008). The contermeasures of urban land intensive use in hilly area. Journal of Leshan teachers college, 23(9), 128-131.

Luo, Xinmao, He, Hongwei, \& Ke, Xinli. (2009). Evaluation on urban land intensive use based on AHP. Journal of Anhui agri. Sci, 37(36), 18114-18116.

Song, Hongmei, \& Hou, Huping. (2007). The evaluation of urban land intensive utilization base on entropy method — case study in Xuzhou. Resource development and market, 23(2), 116-118.

Tao, Zhihong. (2000). The discussion about several basic problems of urban land intensive utilization. China land science, 14(5), 1-5.

Wang, Xiaoyan, Deng, Liangji, Zheng, Huawei, \& Deng, Yunsi. (2008). Land intensive use level and influencing factors in Chengdu. Scientific and technological management of land and resources, 25(3), 
69-73.

Wang, Xiaowei, \& Li, Minghui. (2009). The city land intensive use evaluation research in Changsha. The border economy and culture, (2), 49-50.

Yang, Donglang, Zhang, Xiaoming, \& Liu, Ping. (2008). The evaluation of urban land intensive use based on PSR model. Journal of Shaanxi normal university (Natural science edition), 36(1), 90-93.

Yang, Jianbo, \& Wang, Li. (2007). The research of the urban land intensive use level. Scientific and technological management of land and resources, 24(3), 40-44.

Yang, Shuhai. (2007). The connotation of urban land intensive utilization and the construction of evaluation index system. Inquiry into economic issues, (1), 27-30.

Zhan, Haibin, \& Wu, Qun. (2009). Analysis on spatial difference of urban land intensive use based on PSR model-A case study of Jiangsu Province. System sciences and comprehensive studies in agriculture, 25(4), 396-400.

Zheng, Xinqi. (2004). Optimized configuration and intensive use evaluation of urban land-the theory, method, technology and demonstration. Science press.

Zhu, Yougai. (2010). Evaluating the land intensive utilization in Fujian based on Entropy Method. Taiwan agricultural research, (4), 57-59. 